\title{
O que é e por que alguém estuda a leitura?
}

Sentando em frente à tela de teu computador, você começa a ler a Revista Criação \& Crítica de número 9. Teus olhos percorrem o colorido da capa, deslizando por sobre as letras do editorial. Na maior parte das vezes, você não lê o editorial de revistas on-line, pois vai direto aos artigos; é preciso, contudo, descobrir caminhos, clicar e se permitir perambular por entre textos que não te interessavam. Agora que lê esse editorial, provavelmente está sendo guiado por um desejo de orientação. Nessa busca, teus olhos deparam-se com o título: O que é e por que alguém estuda a leitura? Você percebe, então, que o dossiê deste número é justamente sobre a leitura, atividade que está exercendo nesse mesmo momento.

É possível que tenha imaginado que haverá textos sobre imagens de leitores ou ensino da literatura. É o que aparece quando teus olhos deslizam pelo título do primeiro artigo:

"Mutações epistemológicas e o ensino da literatura: o advento do sujeito leitor", de Annie Rouxel.

Talvez queira ler porque se trata de um artigo sobre as alterações na representação que a teoria literária fez sobre o leitor realizadas durante a segunda metade do século XX e o impacto que isso teve (ou deve ter) no ensino da literatura na

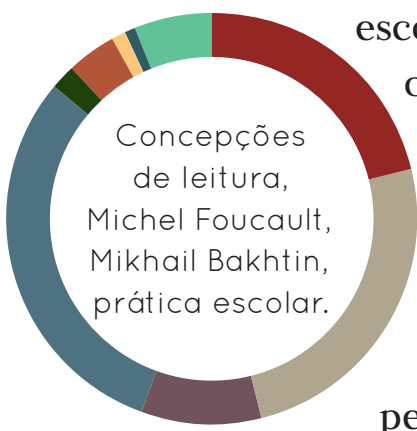

escola e na universidade. Você lê também que o segundo texto,

"Leitura literária: provocações para

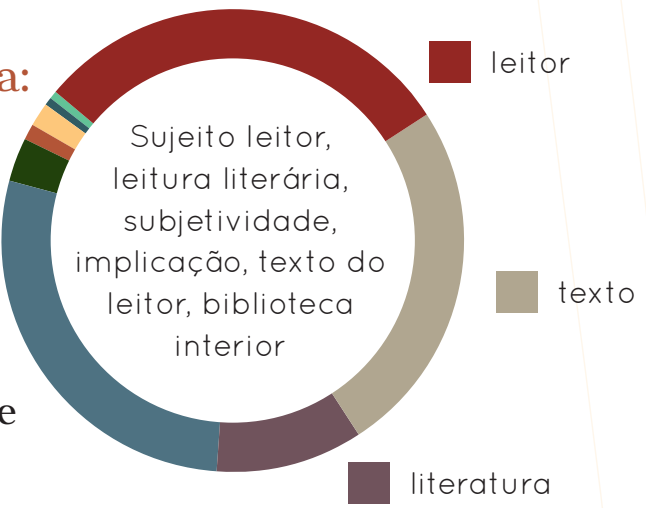
pensar o contexto escolar", de Maria de Fátima Cruvinel, assemelha-se ao debate de Annie Rouxel, pois discute teoricamente a leitura com o mesmo propósito, mas por caminho diverso e complementar para pensar a leitura e o ensino. O texto seguinte, "Raul Pompeia, Abílio César Borges e a escola brasileira no século XIX”, de Regina Zilberman, por discutir a representação do sistema escolar brasileiro, principalmente a figura de Abílio César Borges na obra de Raul Pompeia, é um desdobramento analítico da reflexão sobre a relação literatura e ensino que perfaz o primeiro bloco do dossiê o que é e por que alguém estuda a leitura?

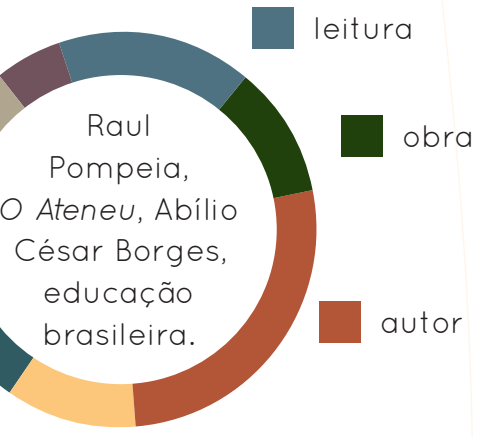

Matutando sobre essa pergunta e sobre a relação leitura-ensino, você se depara com outro texto:

"A estética da recepção: o leitor na economia do texto e da história”, de Jefferson Cleiton de Souza, que vai tentar te mostrar como a estética da recepção desenvolvida por Hans Robert Jauss articula a noção de leitor à economia do texto literário e à história por meio da discussão dos conceitos de leitor implícito, leitor explícito e experiência estética.

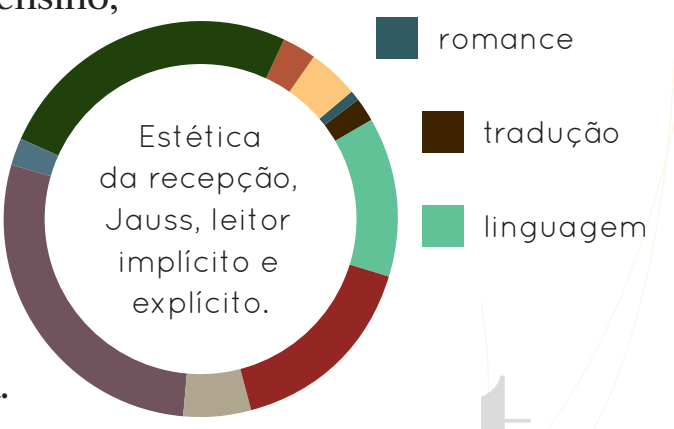


Ora, continuando a percorrer o texto, você descobre que essas questões teóricas são retomadas por Janine Resende Rocha em

"O espaço da fícção e os limites do sentido", no qual são discutidas as condições de emergência do sentido, investigando a hermenêutica literária a partir de um romance de Franz Kafka.

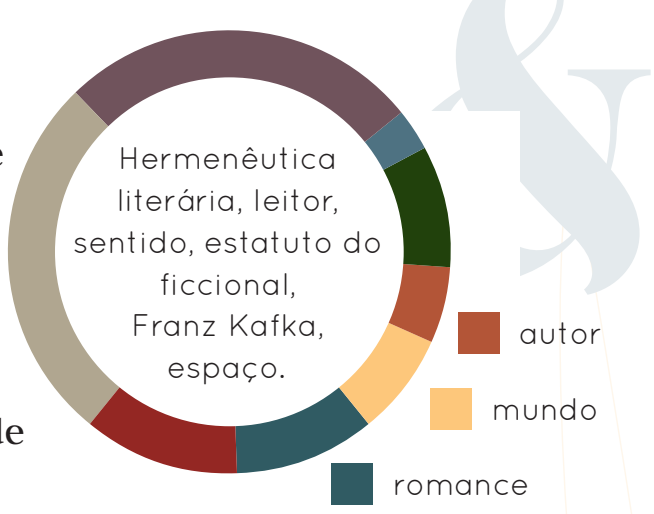

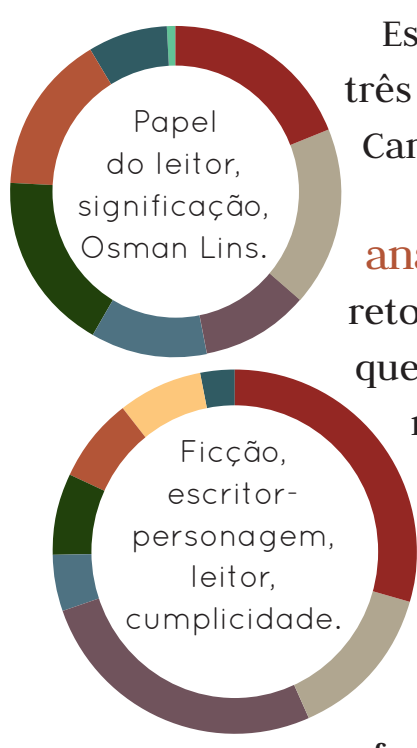

Essa incursão na análise literária, você lê, é mantida nos próximos três textos, nos quais se discute a figuração da escrita e da leitura. Carolina Duarte Damasceno, em

"O leitor e as mudanças no processo de significação: uma análise de A rainha dos cárceres da Grécia de Osman Lins", retoma a discussão sobre a construção do sentido em um romance que relata, justamente, o processo de leitura e interpretação de um romance fictício por seu narrador, numa exposição dos bastidores da leitura e da ficção literária. Essa exposição é evidenciada por Igor Ximenes Graciano, em

"O leitor cúmplice em Sérgio Sant’anna", que mostra como ela participa de um jogo de cumplicidade com o leitor. Teus olhos então se deparam com o nome de um escritor francês no título do próximo artigo do dossiê:

"Entre a sedução e a desconfiança - o jogo do autor e do leitor em Les faux monnayeurs de André Gide”, de Isabelle Santos Bezerra. Você lê que a figuração do autor empreendida por Gide no romance de 1925 é complexa, porque o escritor, apresentando também o diário que escrevera durante a redação do romance, desestabiliza as fronteiras entre a leitura autobiográfica e ficcional. Essa desestabilização da leitura, desta vez pelo arranjo estrutural do romance de Herman Hesse, continua, você percebe, em

"O lobo da estepe: uma escritura selvagem", de Gabrielle da Silva Foster, último artigo do dossiê.

E,assim, dedesestabilizaçãoemdesestabilização,vocêpassaparaostítulos detemáticalivre-masalguns dialogam(comdiferentesintensidades) comodossiê.Umtemaemcomumentreos títulos que você lê agora é o autor observado em sua atividade de leitura: Álvaro Cardoso Gomes sublinha a influência

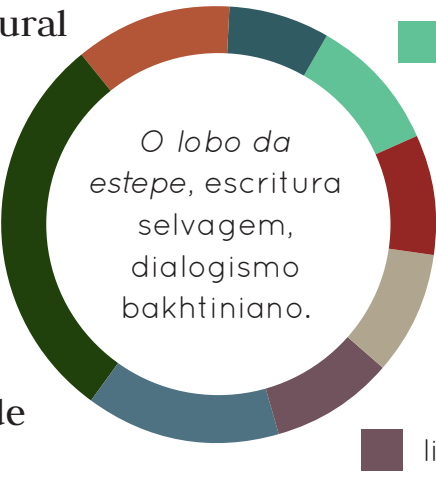
linguagem do misticismo na construção das imagens místico-estéticas do poema "Correspondências" no artigo "Baudelaire e a linguagem das correspondências". De volta ao Brasil, você descobre em "A biblioteca fantástica de Mário de Andrade", de Aline Novais de Almeida, que se pode pensar nas leituras de um escritor a partir das marcas que deixou em seus livros (biblioteca física) e da leitura intervalar que desencadeia um novo processo criativo (biblioteca fantástica). Você percebe, então, que estamos nos preparando para falar novamente de literatura estrangeira, 
mas antes verá que Monteiro Lobato, autor preocupado em formar um público leitor desde a infância, é o objeto do próximo artigo, de Daniella Amaral Tavares. Intitulado "O Minotauro: ausências e substituições em Lobato", ele traz uma reflexão sobre o processo de adaptação da mitologia para crianças.

Você percebe então que a estrutura do texto literário comporta a experiência de estranheza, que deve ser mantida quando ocorre sua tradução para outra língua, como defende Emilia Pereira Chanut, em "A tradução ética em A prova do estrangeiro". Ora, o problema do registro da experiência, mais particularmente da experiência da violência nas ciências humanas é o tema do artigo de Enrique Nuesch, "Por uma Biagraphia: notas sobre o registro da violência”, que desenvolve essa ideia por meio das reflexões sobre a linguagem em Saussure, Bourdieu e Derrida. O problema da linguagem, principalmente da relação linguística da palavra com o mundo é, você lê então, o tema central de Vinícius Pacheco Gonçalves em "Clarice Lispector e Stéphane Mallarmé: a orquestração do rumor", que tenta aproximar o poeta francês e a ficcionista brasileira por meio de suas atitudes frente à linguagem. É nessa linha de comparação dos procedimentos que Patrícia de Oliveira Leme opera a aproximação entre Freud e Borges em "Moisés sob investigação: Sigmund Freud e o labirinto borgeano", para mostrar como o cunho investigativo de um ensaio freudiano e de um conto borgeano afetam a relação do leitor com o texto, reestruturando o ato de leitura.

Com o tema da leitura novamente em foco, você se dá conta de que já está na seção “Traduções”. É possível que fique surpreso ao ler o nome de Jauss, um dos fundadores da estética da recepção, na revista. Traduzido por Samara Geske, o artigo "Recepção e produção: o mito dos irmãos inimigos" aborda as duas pontas da experiência estética, a escrita e a leitura literárias, propondo-se a mostrar que é preciso romper com um mito de que se trata de problemas opostos para a compreensão estética. Você lê agora que a segunda tradução, feita por Luís Roberto Amabile, também participa do dossiê; trata-se do texto de Guy de Maupassant, "Estudo sobre o romance", de 1888, que é a resposta do contista para as críticas dos críticos literários acerca do romance Pedro e João. Você lê que o último texto deste número (ou talvez você perceba só agora que ele tenha sido o último, porque pode ter começado a ler este editorial por causa dele) é a tradução do artigo "Sobre algumas genealogias e formas do hibridismo na literatura do século XX", de Vladimir Krysinski, feita por Zênia de Faria, que trata do conceito de hibridismo na literatura, um dos aspectos essenciais do discurso literário, mas que participa também das reflexões de diversas disciplinas.

E, assim, de linha em linha, você chega ao fim da leitura do editorial e, olhando em volta, você percebe que está sentando à frente de sua tela de computador, lendo a revista Criação \& Crítica. Algumas de suas expectativas devem ter sido atendidas. Talvez você também tenha experimentado alguma surpresa. Mas o principal é que esteja curioso. Vamos. Passe aos artigos. Veja que história, na rede de linhas que se entrelaçam, na rede de linhas que se entrecruzam, espera seu fim.

Mônica Gama

Samira Murad

Editoras Executivas
Claudia Amigo Pino

Eitora Científica 